\title{
In Situ Doping of Nitrogen in $<110>$-Oriented Bulk 3C-SiC by Halide Laser Chemical Vapour Deposition
}

\author{
Youfeng Lai ${ }^{1}{ }^{1}$, Lixue Xia ${ }^{1}$, Qingfang $\mathrm{Xu}^{2}{ }^{2}$, Qizhong $\mathrm{Li}^{1}{ }^{1}, \mathrm{Kai}_{\mathrm{Liu}}{ }^{3}$, Meijun Yang ${ }^{1}$, \\ Song Zhang ${ }^{1 \oplus}{ }^{1}$, Mingxu Han ${ }^{4}$, Takashi Goto ${ }^{1,5}$, Lianmeng Zhang ${ }^{1}$ and Rong Tu ${ }^{1, *}$ \\ 1 State Key Laboratory of Advanced Technology for Materials Synthesis and Processing, \\ Wuhan University of Technology, 122 Luoshi Road, Wuhan 430070, China; 19951114@whut.edu.cn (Y.L.); \\ xlxwhutmail@163.com (L.X.); qizhongli@whut.edu.cn (Q.L.); liyangmeijun@163.com (M.Y.); \\ superkobe0104@gmail.com (S.Z.); goto@imr.tohoku.ac.jp (T.G.); lmzhang@whut.edu.cn (L.Z.) \\ 2 School of Optical and Electronic Information, Huazhong University of Science and Technology, \\ No. 1037 Luoyu Road, Wuhan 430070, China; 2019508016@hust.edu.cn \\ 3 Materials Science and Engineering, Wuhan University of Technollogy, 122 Luoshi Road, \\ Wuhan 430070, China; victor_liu@whut.edu.cn \\ 4 R \& D, Ibiden Co., Ltd., 1-1 Kitagata, Ibigawa-cho, Ibi-gun, Gifu 501-0695, Japan; han_mingxu@ibiden.com \\ 5 New Industry Creation Hatchery Center, Tohoku University, Sendai 980-8579, Japan \\ * Correspondence: turong@whut.edu.cn
}

Received: 9 December 2019; Accepted: 9 January 2020; Published: 15 January 2020

\begin{abstract}
Doping of nitrogen is a promising approach to improve the electrical conductivity of 3C-SiC and allow its application in various fields. N-doped, $<110>$-oriented $3 \mathrm{C}$-SiC bulks with different doping concentrations were prepared via halide laser chemical vapour deposition (HLCVD) using tetrachlorosilane $\left(\mathrm{SiCl}_{4}\right)$ and methane $\left(\mathrm{CH}_{4}\right)$ as precursors, along with nitrogen $\left(\mathrm{N}_{2}\right)$ as a dopant. We investigated the effect of the volume fraction of nitrogen $\left(\phi_{\mathrm{N} 2}\right)$ on the preferred orientation, microstructure, electrical conductivity $(\sigma)$, deposition rate $\left(R_{\text {dep }}\right)$, and optical transmittance. The preference of 3C-SiC for the $\langle 110\rangle$ orientation increased with increasing $\phi_{\mathrm{N} 2}$. The $\sigma$ value of the $\mathrm{N}$-doped $3 \mathrm{C}$-SiC bulk substrates first increased and then decreased with increasing $\phi_{\mathrm{N} 2}$, reaching a maximum value of $7.4 \times 10^{2} \mathrm{~S} / \mathrm{m}$ at $\phi_{\mathrm{N} 2}=20 \%$. $R_{\text {dep }}$ showed its highest value $(3000 \mu \mathrm{m} / \mathrm{h})$ for the undoped sample and decreased with increasing $\phi_{\mathrm{N} 2}$, reaching $1437 \mu \mathrm{m} / \mathrm{h}$ at $\phi_{\mathrm{N} 2}=30 \%$. The transmittance of the $\mathrm{N}$-doped $3 \mathrm{C}-\mathrm{SiC}$ bulks decreased with $\phi_{\mathrm{N} 2}$ and showed a declining trend at wavelengths longer than $1000 \mathrm{~nm}$. Compared with the previously prepared <111>-oriented N-doped $3 \mathrm{C}$-SiC, the high-speed preparation of $<110>$-oriented N-doped 3C-SiC bulks further broadens its application field.
\end{abstract}

Keywords: N-doped \&lt; 110\&gt; -oriented 3C-SiC bulk; preferred orientation; conductive SiC; halide laser CVD

\section{Introduction}

Silicon carbide $(\mathrm{SiC})$ is a promising electronic material, which has been applied in various fields due to its excellent mechanical properties, chemical stability, and high durability [1,2]. Although $\mathrm{SiC}$ is an intrinsic semiconductor, a high electrical conductivity $(\sigma)$ is a necessary requirement for certain applications, such as solar cells [3], electromagnetic shielding materials [4], pressure sensors [5], and electro-discharge machining [6]. In situ doping via chemical vapour deposition (CVD) is a common method to improve the electrical conductivity of intrinsic semiconductors and allow its application in various fields, such as diamond, $\mathrm{ZnO}, \mathrm{TiO}_{2}$, etc. [7-9]. In recent decades, a great deal of work has been focused on the preparation of $\mathrm{N}$-doped SiC by adding $\mathrm{NH}_{3}[5,10]$ or $\mathrm{N}_{2}$ [11,12] during CVD, achieving $\sigma$ values from 0.1 to $10^{3} \mathrm{~S} / \mathrm{m}$. However, the deposition rates $\left(R_{\text {dep }}\right)$ were limited to values between 
0.1 and $10 \mu \mathrm{m} / \mathrm{h}$ [10-14]. Due to the low deposition rate, conventional CVD is usually effective for preparing $\mathrm{SiC}$ films but not bulk crystals, which greatly limits the applications of doped $\mathrm{SiC}$.

Our research group has recently developed an efficient halide laser CVD (HLCVD) process to fabricate dense and pure 3C-SiC bulks with high $R_{\text {dep }}$, including transparent 3C-SiC bulks with low defect density and highly preferred orientations [15-17]. The maximum $R_{\text {dep }}$ of 3C-SiC prepared by HLCVD reached $3600 \mu \mathrm{m} / \mathrm{h}$, which is 10 to $10^{3}$ times greater than that of conventional CVD. Preferred orientation has a great influence on the properties of corresponding crystals, for example, $<111>$-oriented 3C-SiC has higher hardness than that of $<110>$ - and $<111>$ co-oriented [15], $<110\rangle$ 3C-SiC can be used in biosensors by modifying it using an organic molecule [18]. Although 3C-SiC prepared by CVD usually exhibit $<111>$ and $<110>$ preferred orientations, the doped 3C-SiC obtained in previous studies showed an almost exclusively $<111>$ orientation. Nevertheless, the $<110>$-oriented 3C-SiC may be a more sensitive structural material and could be applied to pressure sensors in microelectromechanical systems (MEMS) [19], due to its lower Young's modulus (about 350 GPa) than that of the $<111>$-oriented 3C-SiC (about $500 \mathrm{GPa}$ ).

$\mathrm{NH}_{3}$ is an effective and widely used precursor in $\mathrm{N}$-doped $\mathrm{SiC}$, but in the chloride precursor system, especially when the flow rate of the precursor is large, $\mathrm{NH}_{3}$ reacts violently with chloride to form ultra-fine powdery by-products and easily block the pipeline and vacuum pump. In addition, large amounts of $\mathrm{Si}-\mathrm{N}$ bonds are easily generated due to the high reactivity of $\mathrm{NH}_{3}$. On the contrary, although the reaction activity of nitrogen is low, $\mathrm{N}_{2}$ is often used as the precursor of semiconductor doping because of its good safety and large flow regulation range. In our previous study, we showed that laser CVD can rapidly produce highly $<110>$-oriented 3C-SiC at a relatively low temperature (approximately $1523 \mathrm{~K}$ ) [15]. To obtain a $<110>$-oriented 3C-SiC bulk with high electrical conductivity at high $R_{\text {dep }}$, in situ nitrogen doping was conducted by adding nitrogen during the preparation of 3C-SiC via HLCVD. In this study, we prepared thick, conductive, and N-doped $<110>$-oriented 3C-SiC bulks and investigated the effect of the volume fraction of $\mathrm{N}_{2}\left(\phi_{\mathrm{N} 2}\right)$ on their preferred orientation, deposition rate, electrical conductivity, and optical transmittance. This study provides a new promising route for the rapid fabrication of various doped bulk semiconductors with specific preferred orientation.

\section{Experimental}

A cold wall HLCVD apparatus was developed to fabricate N-doped 3C-SiC bulks. Figure 1 shows the diagram of the HLCVD apparatus. Graphite discs (IGS-743, $\phi=15 \mathrm{~mm} \times 1 \mathrm{~mm}$, Sankyo Carbon, Tokyo, Japan) were used as substrates and heated on a heating stage at a temperature of $773 \mathrm{~K}$ before deposition. A diode laser beam (InGaAlAs, $\lambda=1060$ nm, BEIJING ZK Laser Co., Ltd., Beijing, China) was introduced into the chamber through a quartz window and its diameter was enlarged to $20 \mathrm{~mm}$ by a lens to cover the entire substrate. The deposition temperature $\left(T_{\mathrm{dep}}\right)$ was measured with a pyrometer (2MH-CF4, Optris $\mathrm{GmbH}$, Berlin, Germany) and automatically controlled at $1623 \mathrm{~K}$ by a computer. The error in the surface temperature of the entire graphite substrate was $\pm 5 \mathrm{~K} \mathrm{SiCl}_{4}$ and $\mathrm{CH}_{4}$ were used as precursors and $\mathrm{N}_{2}$ as dopant. Liquid $\mathrm{SiCl}_{4}$ was evaporated into a gas by an evaporator at a temperature of $353 \mathrm{~K}$ before being carried into the CVD chamber. The flow rates of $\mathrm{SiCl}_{4}, \mathrm{CH}_{4}$, and $\mathrm{H}_{2}$ were fixed at 600, 200, and $1200 \mathrm{sccm}$, respectively (the flow rate of $\mathrm{SiCl}_{4}$ was converted from liquid to gas units), whereas the flow rate of $\mathrm{N}_{2}$ was controlled to $5 \%$ to $30 \%$ of the total gas. The total pressure $\left(P_{\text {tot }}\right)$ and deposition time were set to $4 \mathrm{kPa}$ and $15 \mathrm{~min}$, respectively. The distance between the graphite substrate and the nozzle was $30 \mathrm{~mm}$. The nozzle temperature was set to $473 \mathrm{~K}$. An exhaust gas treatment system composed of a cold trap filled with liquid nitrogen, an activated carbon filter, and an $\mathrm{NaOH}$ spray scrubber was used for the disposal of the harmful acidic intermediates. Table 1 summarises the main deposition parameters used for the preparation of $\mathrm{N}$-doped 3C-SiC bulks. 


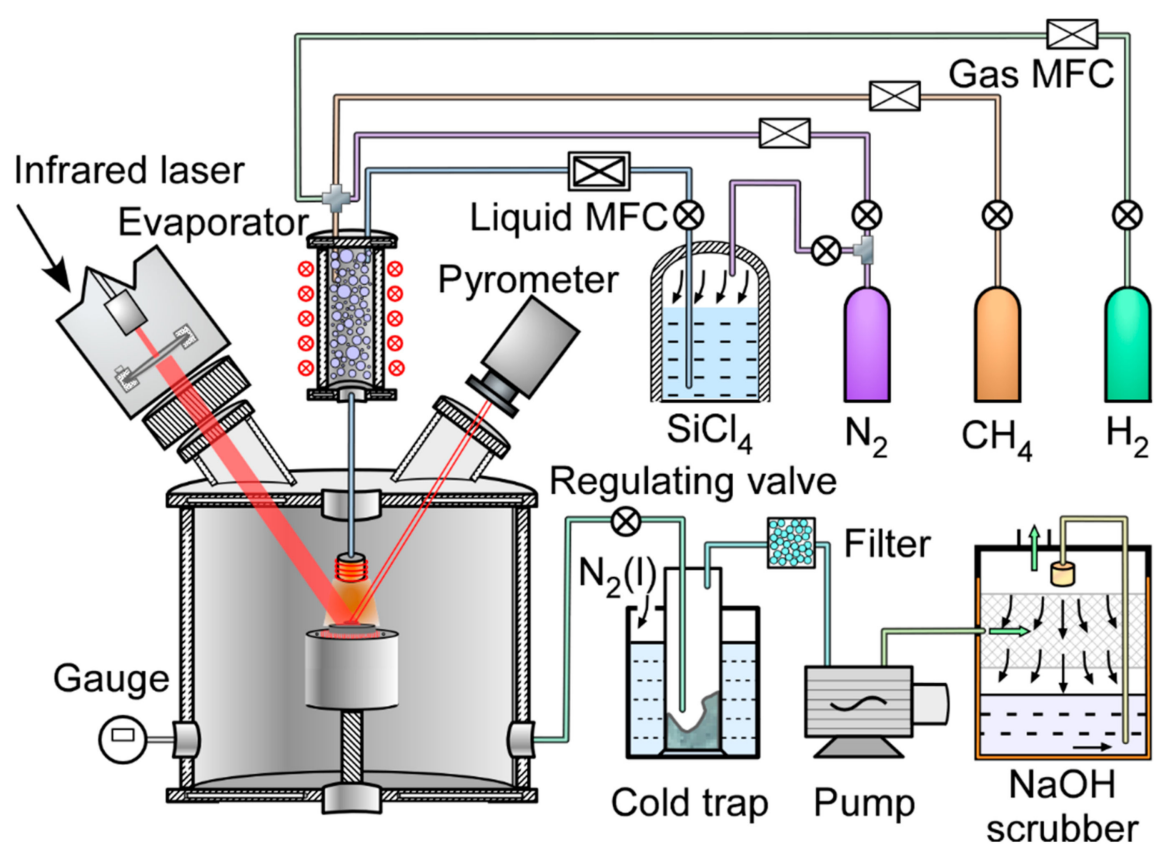

Figure 1. Schematic illustration of the HLCVD apparatus.

Table 1. Deposition parameters.

\begin{tabular}{ll}
\hline \multicolumn{1}{c}{ Precursor } & \multicolumn{1}{c}{$\mathrm{SiCl}_{\mathbf{4}}+\mathrm{CH}_{\mathbf{4}}$} \\
\hline Diluting gas & $\mathrm{H}_{2}$ \\
Dopant & $\mathrm{N}_{2}$ \\
Substrate & $\mathrm{Graphite}$ \\
$T_{\text {dep }}$ & $1623 \mathrm{~K}$ \\
$P_{\text {tot }}$ & $4 \mathrm{kPa}$ \\
Flow rate of $\mathrm{SiCl}_{4} / \mathrm{CH}_{4}$ & $600 / 200 \mathrm{sccm}$ \\
Flow rate of $\mathrm{H}_{2}$ & $1200 \mathrm{sccm}$ \\
$\phi_{\mathrm{N} 2}$ & $0-30 \%$ \\
Distance between the nozzle and the substrate & $30 \mathrm{~mm}$ \\
Deposition time & $20 \mathrm{~min}$ \\
\hline
\end{tabular}

The crystalline phases of the deposited samples were analysed by $\theta-2 \theta$ X-ray diffraction (XRD) with $\mathrm{Cu} \mathrm{K} \mathrm{K}_{\alpha}$ radiation at $40 \mathrm{kV}$ and $40 \mathrm{~mA}$ (Ultima III, Rigaku, Tokyo, Japan). The microstructure and thickness of the deposits were inspected by field emission scanning electron microscopy (FESEM, Quanta-250, FEI, 20 kV, Houston, TX, USA). Raman spectra were measured by a LabRam HR800 Ev (Horiba, Tokyo, Japan) spectrometer equipped with a $532 \mathrm{~nm}$ He-Ne laser. The transmittance was measured in the wavelength range of 250 to $2000 \mathrm{~nm}$ using a UV-Vis-near infrared (NIR) spectrophotometer (Lambda 750 S, PerkinElmer, Waltham, MA, USA). Before testing the optical transmittance of $3 \mathrm{C}-\mathrm{SiC}$, the thick deposits were removed from the graphite substrate by a diamond grinding disc and polished into a mirror surface on both sides using diamond slurries of diameters 9,3 , and $1 \mu \mathrm{m}$. The final thicknesses of the 3C-SiC bulks were approximately $250 \mu \mathrm{m}$. The electrical conductivity and Hall coefficient of the 3C-SiC bulks were measured by a self-assembled electric and magnetic performance testing system. The elemental composition of the N-doped 3C-SiC bulks was analysed by X-ray photoelectron spectroscopy (XPS, ESCALAB 250Xi, Thermo Fisher Scientific, MA, USA). To prevent surface contamination from affecting the results, all samples were argon-etched prior to testing. The Seebeck coefficients were determined using a portable tester (PTM-3, Jouleyacht, Wuhan, China). 


\section{Results and Discussion}

Figure 2a shows typical XRD patterns of the 3C-SiC bulks prepared by HLCVD with $\phi_{\mathrm{N} 2}$ values up to $30 \%$. No traces of second phases were detected in the XRD patterns. A small shoulder observed at $2 \theta \sim 33.8^{\circ}$ could be attributed to planar defects [20-22]. All specimens deposited at $T_{\text {dep }}=1623 \mathrm{~K}$ and $P_{\text {tot }}=4 \mathrm{kPa}$ exhibited a $<110>$ preferred orientation. Figure $2 \mathrm{~b}$ shows the Lotgering factors $\left(F_{\mathrm{hkl}}\right)$ and lattice constants $(a)$ of the N-doped 3C-SiC samples. $F_{\text {hkl }}$ was calculated from Equation (1) [23]:

$$
F_{h k l}=\left(P_{h k l}-P_{0}\right) /\left(1-P_{0}\right)
$$

where $P_{\mathrm{hkl}}$ and $P_{0}$ are the ratios of the peak intensity of the $(h k l)$ planes to the sum of the intensities of all peaks for the films $\left(P_{\mathrm{hkl}}\right)$ and powders $\left(P_{0}\right)$, respectively. The values of $F_{\mathrm{hkl}}$ range from negative (orientation along the other axes) to 0 (random) to 1 (perfect orientation). The $F_{110}$ value of undoped $3 \mathrm{C}-\mathrm{SiC}$ was 0.774 and increased with increasing $\phi_{\mathrm{N} 2}$, reaching 0.945 at $\phi_{\mathrm{N} 2}=30 \%$. To the best of our knowledge, this is the first report of N-doped $3 \mathrm{C}-\mathrm{SiC}$ with $<110>$ orientation. According to Refs. [24,25], $<111>$-oriented 3C-SiC shows a polar crystal structure containing $\mathrm{Si}\{111\}$ and $\mathrm{C}\{-1-1-1\}$ planes. The substituted $\mathrm{N}$ atoms mostly occupy the $\mathrm{C}$ sites in the $\mathrm{SiC}$ lattice. However, the adsorption of $\mathrm{C}$ or $\mathrm{N}$ on $\mathrm{Si}$ atoms along the Si-terminated surface of $<111>$-oriented 3C-SiC grains during the growth is relatively weak. With increasing $\phi_{\mathrm{N} 2}$, the site competition between $\mathrm{C}$ and $\mathrm{N}$ atoms becomes more intense, which may reduce the growth rate of the $<111>$ orientation and result in the increase of $F_{110}$. The lattice constant $(a)$ of $3 C$-SiC decreased from $4.3707 \AA$ for the undoped sample to $4.3640 \AA$ at $\phi_{\mathrm{N} 2}=$ $30 \%$. Nitrogen doping usually results in the shrinkage of the $\mathrm{SiC}$ lattice, due to the substitution of $\mathrm{N}$ atoms at the $\mathrm{C}$ sites and the smaller covalent radius of $\mathrm{N}(0.70 \AA)$ than that of $\mathrm{C}(0.77 \AA)$ [13].
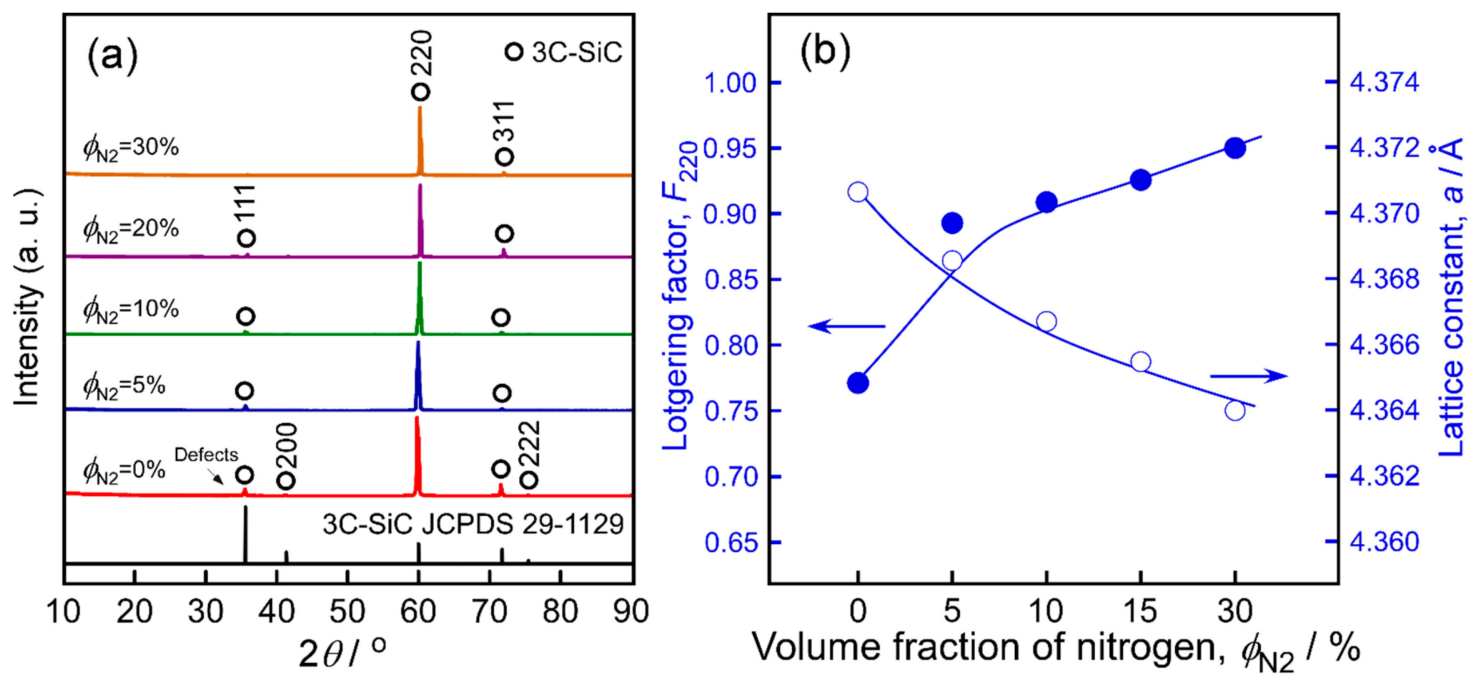

Figure 2. Crystallographic properties of $\mathrm{N}$-doped $3 \mathrm{C}-\mathrm{SiC}$ prepared with different $\phi_{\mathrm{N} 2}$ values. (a) XRD patterns; (b) Lotgering factors $F_{110}$ and corresponding lattice constants.

Figure 3 displays the surface (a-e) and cross-sectional $(\mathrm{f}-\mathrm{j})$ morphologies of $3 \mathrm{C}-\mathrm{SiC}$ bulks prepared with various $\phi_{\mathrm{N} 2}$ values. The undoped 3C-SiC bulk sample shows a cauliflower-like surface structure (Figure 3a) and a columnar cross section (Figure 3f). The cross-sectional morphology of the $\mathrm{N}$-doped 3C-SiC samples are still columnar (Figure 3g-j), while the surface morphology (Figure 3b-e) changed with increasing $\phi_{\mathrm{N} 2}$. The aggregate particle size decreased from approximately $250 \mu \mathrm{m}$ (undoped sample) to $60 \mu \mathrm{m}\left(\phi_{\mathrm{N} 2}=30 \%\right)$, and the morphology gradually changed from cauliflower to fourfold-symmetric pyramid microstructure. The pyramidal grains were considered to be the final stage of the twin-plane propagation model previously proposed for fully $<110>$-oriented 3C-SiC [26]. The change of morphology indicates the enhancement of $<110>$-orientation. However, it is not a complete pyramid structure in Figure $3 e$, indicating that $3 \mathrm{C}-\mathrm{SiC}$ is still not completely $<110>$-oriented 
when nitrogen volume fraction reaches $30 \%$, which is consistent with the XRD results. Figure 4 shows the dependence of the deposition rate on $\phi_{\mathrm{N} 2}$. The $R_{\mathrm{dep}}$ values were calculated from the deposition time and film thickness. With increasing $\phi_{\mathrm{N} 2}, R_{\text {dep }}$ decreased from $3000 \mu \mathrm{m} / \mathrm{h}$ for the undoped sample to $1437 \mu \mathrm{m} / \mathrm{h}$ at $\phi_{\mathrm{N} 2}=30 \%$. As the substitution of $\mathrm{N}$ atoms mostly occurs at the $\mathrm{C}$ sites in the SiC lattice, the dopant may occupy the surface sites of the carbon-containing group, leading to a decrease in the deposition rate [27].
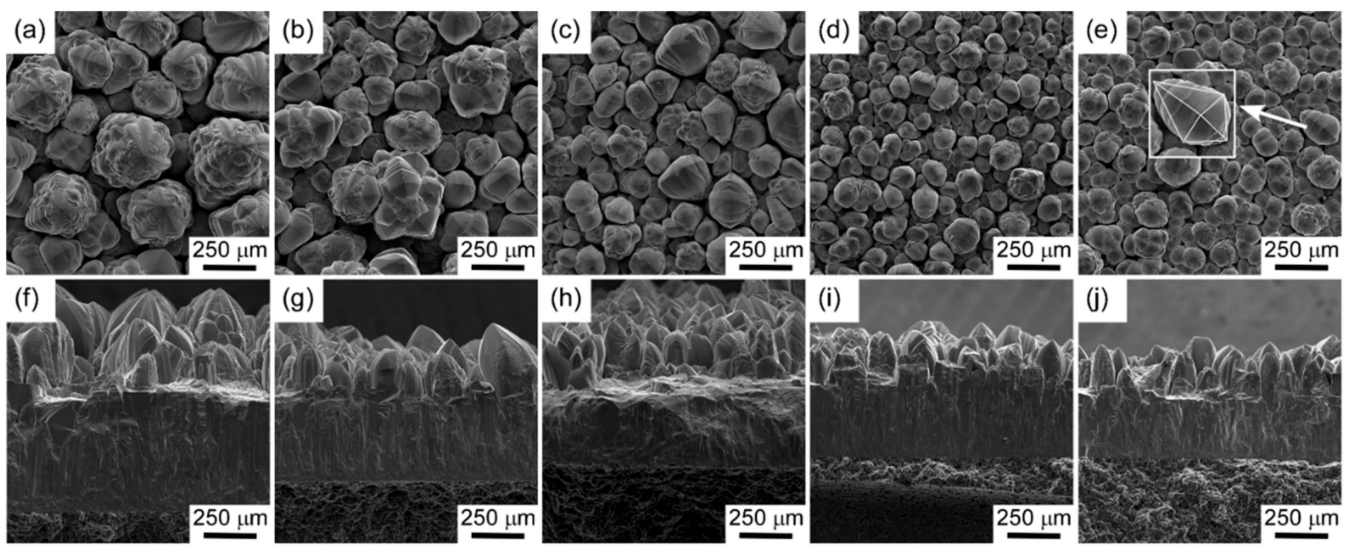

Figure 3. Surface and cross-sectional microstructure of $\mathrm{N}$-doped $3 \mathrm{C}$-SiC bulks obtained at $\mathrm{T}_{\mathrm{dep}}=$ $1623 \mathrm{~K}$ and $P_{\text {tot }}=4 \mathrm{kPa}$, with $\phi_{\mathrm{N} 2}=0 \%(\mathbf{a}, \mathbf{f}), 5 \%(\mathbf{b}, \mathbf{g}), 10 \%(\mathbf{c}, \mathbf{h}), 20 \%(\mathbf{d}, \mathbf{i})$, and $30 \%(\mathbf{e}, \mathbf{j})$.

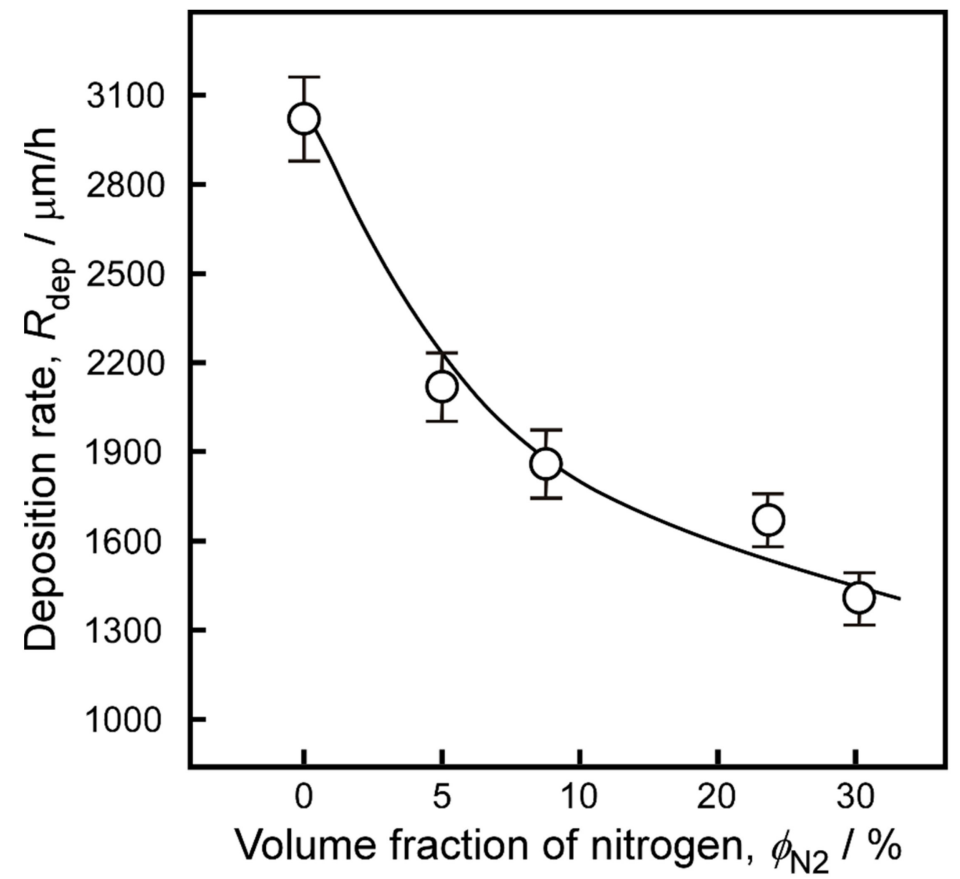

Figure 4. $R_{\text {dep }}$ values of $\mathrm{N}$-doped $3 \mathrm{C}-\mathrm{SiC}$ bulks prepared with different $\phi_{\mathrm{N} 2}$ parameters.

Figure 5 shows the Raman scattering spectra of N-doped 3C-SiC bulks deposited at $T_{\text {dep }}=1623$ $\mathrm{K}$ with different $\phi_{\mathrm{N} 2}$ values. The characteristic Raman modes of pure 3C-SiC primarily consisted of transverse optical (TO) and longitudinal optical (LO) phonons at 796 and $972 \mathrm{~cm}^{-1}$, respectively [28]. This is consistent with the Raman characteristics of the undoped 3C-SiC bulk. However, for $\phi_{\mathrm{N} 2}>$ $5 \%$, the shape of the LO peak of the 3C-SiC bulks showed a marked change, due to Raman scattering from LO phonon-plasmon coupled (LOPC) modes. In a polar semiconductor, the free carrier plasma interacts with the LO lattice vibrations (phonons) via macroscopic electric fields. As a result of this interaction, instead of a pure plasmon and a pure LO phonon, a coupled plasmon-phonon mode appears in the spectrum $[29,30]$. Yugami et al. studied the appearance of the TO and LO peaks in 
$\mathrm{N}$-doped 3C-SiC, and suggested that the increase in carrier concentration due to the incorporation of $\mathrm{N}$ was closely related to the LO peak. The LO peak shifted toward high frequencies and became broader with the decrease in peak intensity as the carrier concentration increased. In contrast, the frequency and full width at half maximum (FWHM) of the TO peaks did not change with the carrier concentration [31]. In this study, the frequency of the LO peak gradually shifted from $972 \mathrm{~cm}^{-1}$ to higher frequencies with increasing $\phi_{\mathrm{N} 2}$. In particular, the frequency of the LO peak reached $997 \mathrm{~cm}^{-1}$ for $\phi_{\mathrm{N} 2}=30 \%$.

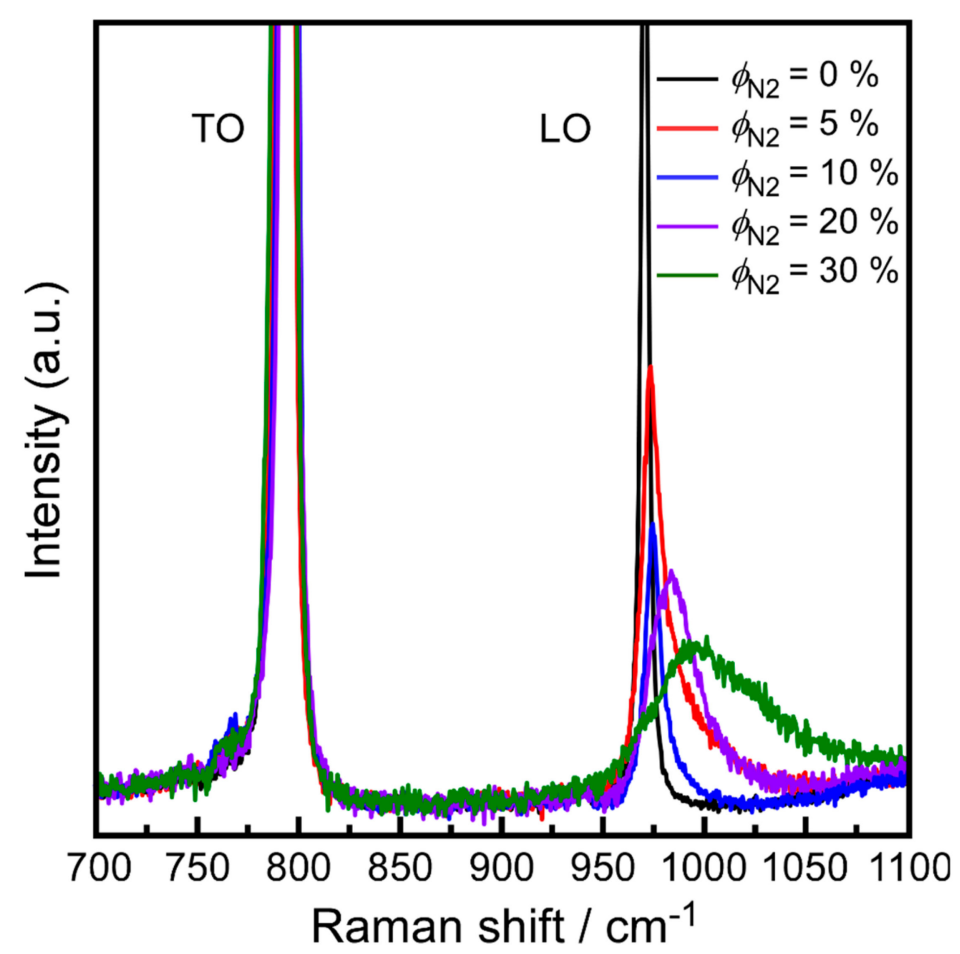

Figure 5. Raman spectra of N-doped 3C-SiC bulks grown with different $\phi_{\mathrm{N} 2}$ values.

Figure 6 displays the transmittance in the UV-Vis-NIR range of N-doped 3C-SiC bulks prepared at $T_{\text {dep }}=1623 \mathrm{~K}$ and $P_{\text {tot }}=4 \mathrm{kPa}$, with different $\phi_{\mathrm{N} 2}$ values. The photographs of the bulks, also shown in Figure 6, reveal that they had a translucent appearance. The differences in the transmittance characteristics of the undoped and N-doped 3C-SiC bulks can be divided into three regions [32,33]. In the low-wavelength region (below $500 \mathrm{~nm}$ ), the fundamental absorption (FA) of N-doped 3C-SiC shifted to high wavelengths; in other words, the bandgap of these samples was shifted to lower energies ("bandgap shrinkage"). In the visible region, the slope of the transmittance curve of N-doped 3C-SiC was lower than that of undoped 3C-SiC, which caused the apparent colour of the doped $\mathrm{SiC}$ to change from yellow to green. The overall transmittance decreased with increasing $\phi_{\mathrm{N} 2}$, resulting in a darker apparent colour of the bulks. In addition, no absorption bands in the below-bandgap region (BGGA), which are usually present in the transmittance spectrum of $\mathrm{N}$-doped $\alpha$-SiC, were observed for N-doped $3 \mathrm{C}-\mathrm{SiC}$, because of the absence of nitrogen donors at inequivalent lattice sites in 3C-SiC [34]. In the NIR region, the transmittance of undoped $3 \mathrm{C}-\mathrm{SiC}$ increased with increasing wavelength, whereas that of $\mathrm{N}$-doped 3C-SiC decreased; this may be due to free carrier absorption (FCA) and is considered to be an intravalence band transition. The peaks between 850 and $950 \mathrm{~nm}$ are generated by the switch between the detector and the light source in the spectrophotometer [35]. 


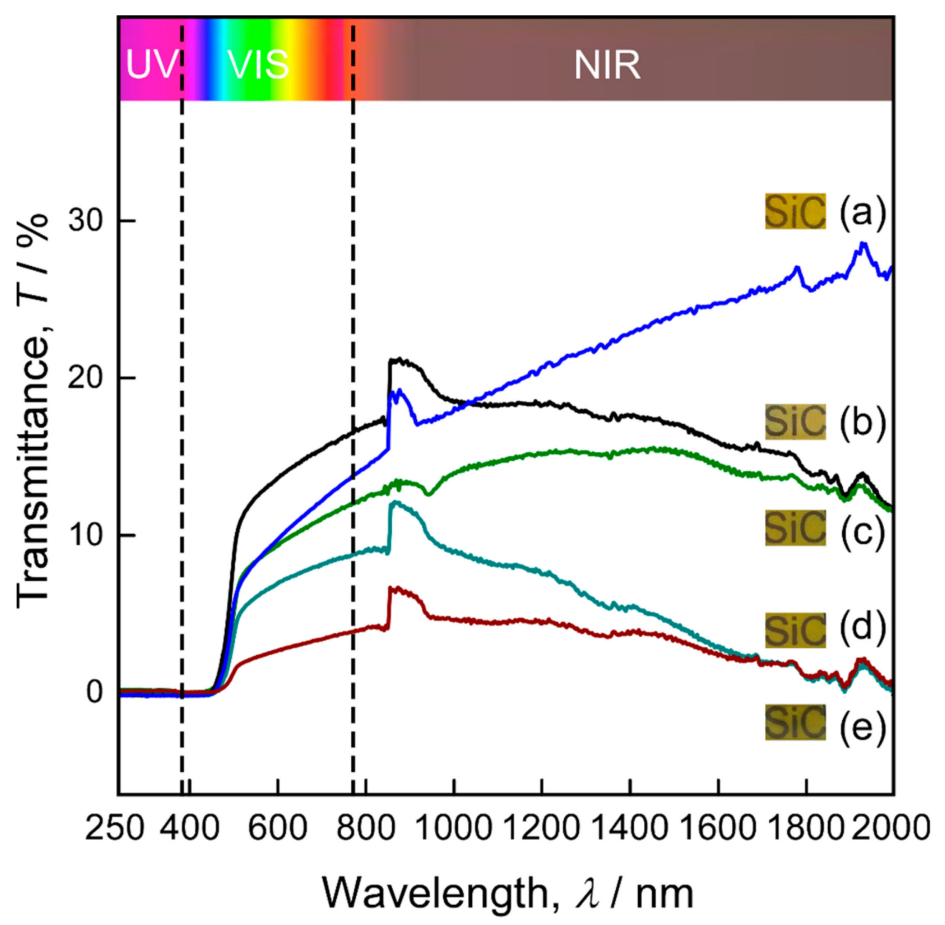

Figure 6. Photograph and optical transmission curves of mirror-polished N-doped 3C-SiC bulks.

Figure 7a shows the electrical conductivity $(\sigma)$, carrier concentration $(n)$, and electron mobility $(\mu)$ of the N-doped 3C-SiC bulks. The $\sigma$ value of the undoped 3C-SiC sample was $7.1 \mathrm{Sm}^{-1}$, and the corresponding intrinsic carrier concentration was $5.7 \times 10^{16} \mathrm{~cm}^{-3}$, which is higher than that reported in the literature $\left(\sim 10^{15} \mathrm{~cm}^{-3}\right)[13,31]$. This means the undoped 3C-SiC may be an unintentionally $\mathrm{N}$-doped sample. The $\sigma$ value of the N-doped 3C-SiC bulks first increased and then decreased with increasing $\phi_{\mathrm{N} 2}$, reaching a maximum of $740.7 \mathrm{Sm}^{-1}$ at $\phi_{\mathrm{N} 2}=20 \%$. When $\phi_{\mathrm{N} 2}$ was further increased, the conductivity showed a slight decrease. Simultaneously, the $\mu$ value of the 3C-SiC bulks decreased from 8.37 to $0.39 \mathrm{~cm}^{2} / \mathrm{V} \cdot \mathrm{s}$ with increasing $\phi_{\mathrm{N} 2}$. The decrease in mobility may be attributed to the decrease in crystallinity or the formation of amorphous $\mathrm{Si}_{3} \mathrm{~N}_{4}$ in the $3 \mathrm{C}-\mathrm{SiC}$ bulks at high $\phi_{\mathrm{N} 2}$ [10]. The corresponding $n$ values increased with increasing $\phi_{\mathrm{N} 2}$, and the highest $n$ of $3.3 \times 10^{19} \mathrm{~cm}^{-3}$ was obtained for the N-doped 3C-SiC bulk deposited at a $\phi_{\mathrm{N} 2}=30 \%$. Figure $7 \mathrm{~b}$ displays the elemental compositions of the 3C-SiC bulks. A stoichiometric 3C-SiC composition was obtained for the undoped sample, and the concentration of $\mathrm{C}$ atoms decreased slightly as $\phi_{\mathrm{N} 2}$ increased. In addition, the nitrogen concentration was two to three orders of magnitudes higher than the carrier concentration. This indicates that most nitrogen atoms are not activated and may be incorporated into the grain boundaries in the form of amorphous nitrogen complexes [13]. Figure 7c shows the Seebeck coefficient of the 3C-SiC bulks at room temperature. All 3C-SiC bulks investigated in this study showed a negative Seebeck coefficient, implying $n$-type conduction. In addition, the absolute value of the Seebeck coefficient decreased with increasing $\phi_{\mathrm{N} 2}$. The Seebeck coefficient and electrical conductivity usually follow an opposite trend as a function of the carrier concentration [36,37]. Figure $7 \mathrm{~d}$ illustrates the temperature dependence of the electrical conductivity. The $\sigma$ values of all 3C-SiC bulks increased with increasing temperature in the range of 295 to $775 \mathrm{~K}$. The activation energy of $\sigma$ was $0.08 \mathrm{eV}$ for the undoped $3 \mathrm{C}-\mathrm{SiC}$ and decreased to $0.03 \mathrm{eV}$ at $\phi_{\mathrm{N} 2}=30 \%$, indicating the presence of a shallow donor level below the conduction band (with energy $E_{\mathrm{N}}=0.03-0.08 \mathrm{eV}$ ) in the 3C-SiC bulks [38]. The slight decrease in activation energy with increasing $\phi_{\mathrm{N} 2}$ has been reported in several studies $[5,13,39]$, and is generally attributed to the decrease in average potential energy of an electron [40]. 

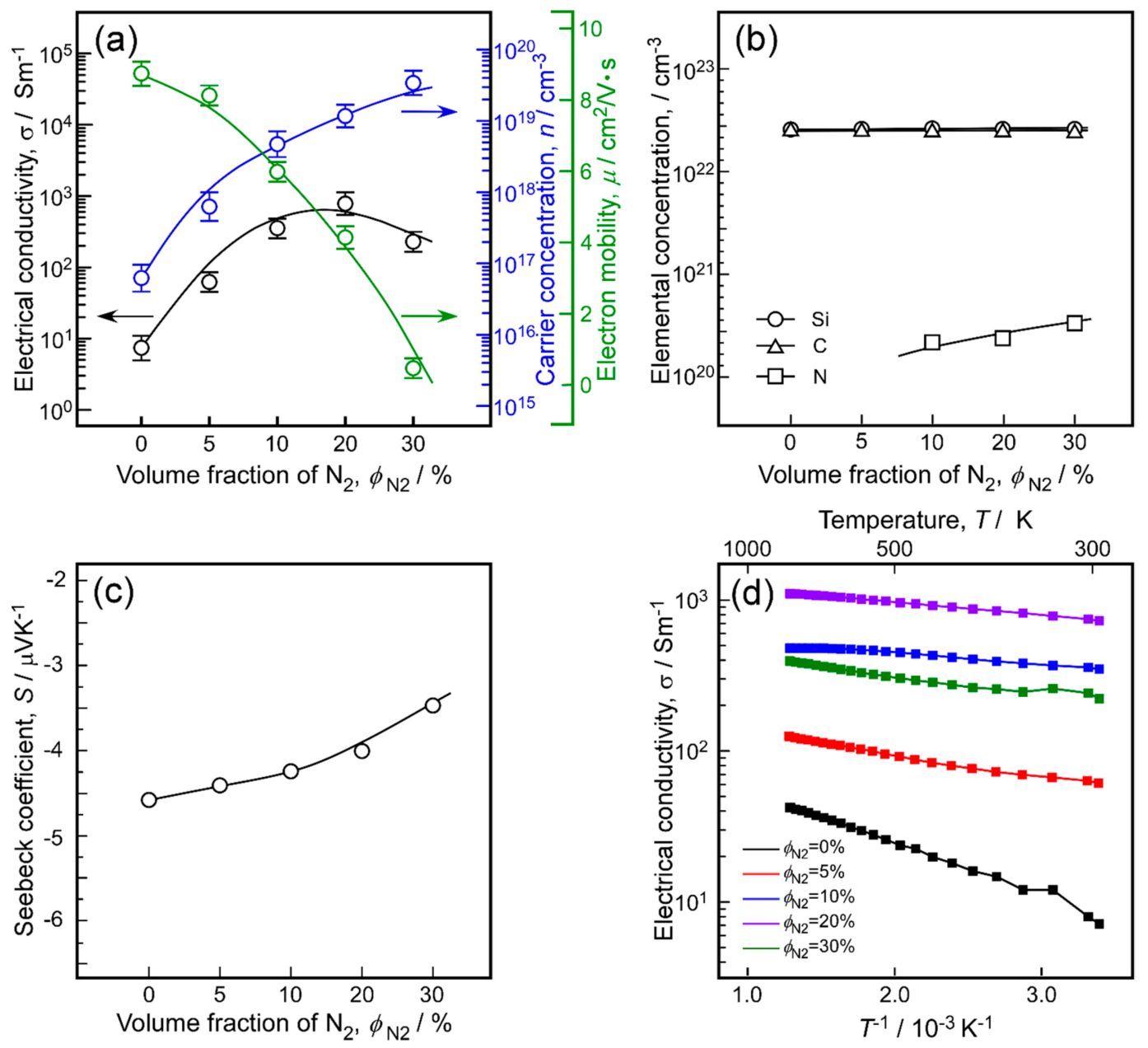

Figure 7. Effect of $\phi_{\mathrm{N} 2}$ on electrical conductivity, carrier concentration, and mobility (a), elemental compositions (b), and Seebeck coefficient (c) of N-doped 3C-SiC bulks. (d) Temperature dependence of electrical conductivities of $\mathrm{N}$-doped 3C-SiC bulks.

Figure 8 compares the electrical conductivity and deposition rate of the $\mathrm{N}$-doped 3C-SiC samples prepared in this study with those reported in the literature [5,10-14,41]. Since most previous studies only provide approximate deposition rates, we assume that they involve a constant deposition rate. Most doped 3C-SiC samples were prepared via conventional CVD using $\mathrm{NH}_{3}$ as dopant, and exhibited $<111>$ but not $<110>$ orientation. The electrical conductivities varied between 33 and $1 \times 10^{4} \mathrm{Sm}^{-1}$ while the deposition rates were in the $0.4-18 \mu \mathrm{mh}^{-1}$ range. The N-doped 3C-SiC bulks prepared via HLCVD in this study exhibited predominant $<110>$ orientation, high deposition rates (1430 to $1670 \mu \mathrm{mh}^{-1}$, between 80 and 4000 times higher than those reported in the literature), and high electrical conductivities $\left(7.4 \times 10^{2} \mathrm{Sm}^{-1}\right)$. 


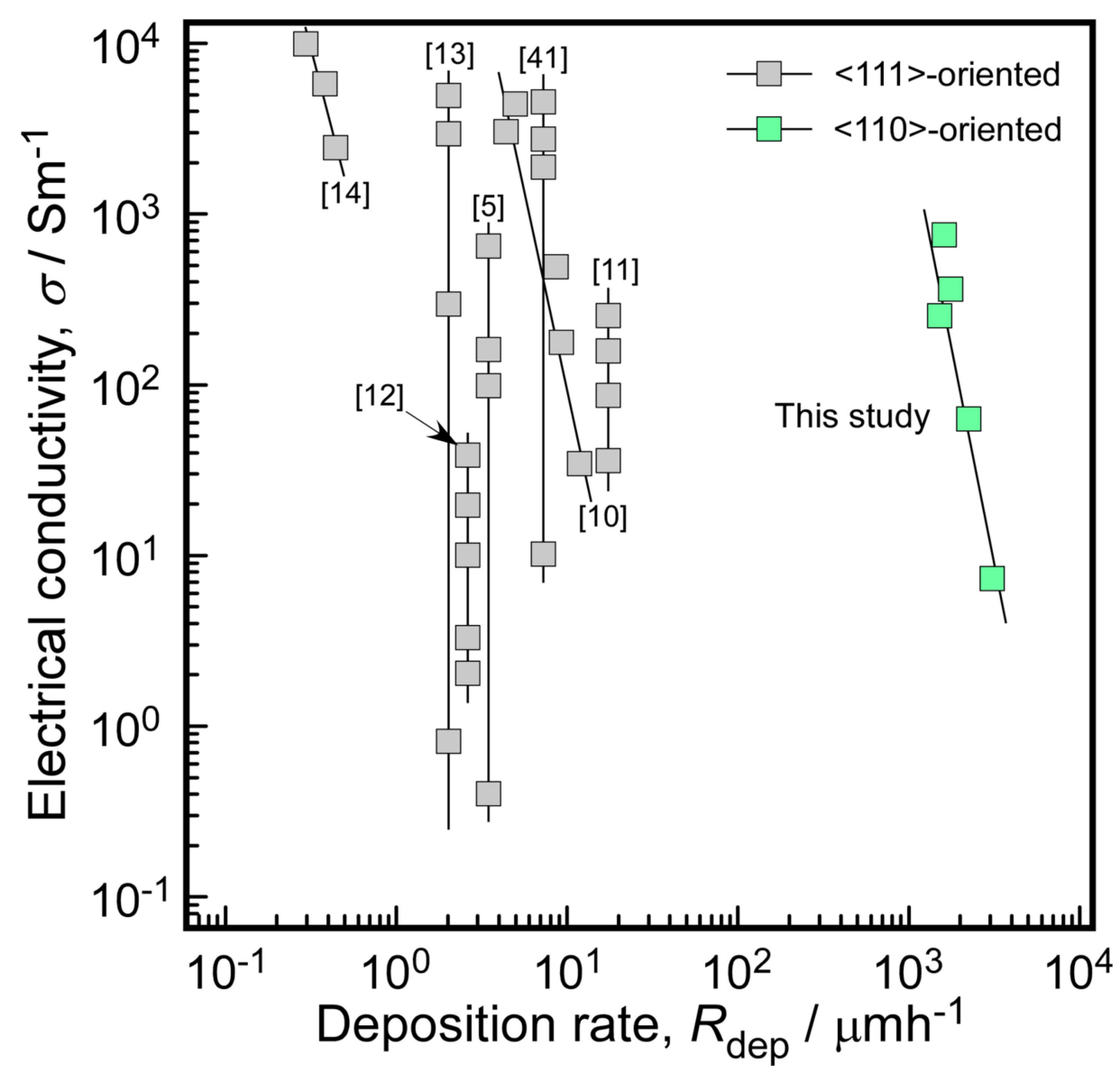

Figure 8. Comparison of electrical conductivities and deposition rates of N-doped 3C-SiC samples prepared via CVD.

\section{Conclusions}

Halide laser chemical vapour deposition is a promising method for obtaining 3C-SiC bulks with predominant $<110>$ orientation and high electrical conductivity at high deposition rates. The degree of $<110>$ orientation of 3C-SiC increased with increasing nitrogen content and became nearly complete at $\phi_{\mathrm{N} 2}=30 \%$, with a Lotgering factor $\left(F_{220}\right)$ of 0.945 . Upon increasing $\phi_{\mathrm{N} 2}$ to $30 \%$, the electrical conductivity and carrier concentration of the N-doped 3C-SiC bulks increased from 7.1 to $740 \mathrm{Sm}^{-1}$ and from $5.7 \times 10^{16}$ to $3.3 \times 10^{19} \mathrm{~cm}^{-3}$, respectively. While the $<110>$-oriented $3 \mathrm{C}$-SiC bulks were translucent, upon nitrogen doping their transmittance decreased with increasing $\phi_{\mathrm{N} 2}$ and also with increasing wavelength. Finally, the $R_{\text {dep }}$ value decreased with increasing $\phi_{\mathrm{N} 2}$, reaching $1437 \mu \mathrm{mh}^{-1}$ at $\phi_{\mathrm{N} 2}=30 \%$, which is 80 to 4276 times higher than that of reported in other studies.

Author Contributions: Conceptualization, Y.L.; Data curation, Y.L.; Formal analysis, L.X., Q.X., K.L., M.Y., S.Z., M.H., T.G. and L.Z.; Funding acquisition, Y.L.; Resources, Q.L.; Writing—original draft, Y.L.; Writing一review \& editing, R.T. All authors have read and agreed to the published version of the manuscript.

Funding: This work was supported by National Natural Science Foundation of China, No. 51372188, No. 51521001, No. 51872212, No. 51861145306 and the 111 Project (B13035). This research was also supported by the International Science \& Technology Cooperation Program of China (2014DFA53090) and the Natural Science Foundation of Hubei Province, China (2016CFA006), and the Fundamental Research Funds for the Central Universities (WUT: 2017-YB-004, 2018III016), and Science Challenge Project (No. TZ2016001), and the State Key Laboratory of Advanced Technology for Materials Synthesis and Processing (WUT, Grant No. 2019-KF-12).

Acknowledgments: We would like to acknowledge support from the center for materials research and analysis of Wuhan University of Technology.

Conflicts of Interest: The authors declare no conflict of interest. 


\section{References}

1. Lee, T.H.; Bhunia, S.; Mehregany, M. Electromechanical computing at $500{ }^{\circ} \mathrm{C}$ with silicon carbide. Science 2010, 5997, 1316-1318. [CrossRef] [PubMed]

2. Barringer, E.; Faiztompkins, Z.; Feinroth, H. Corrosion of CVD silicon carbide in $500^{\circ} \mathrm{C}$ supercritical water. J. Am. Ceram. Soc. 2007, 1, 315-318. [CrossRef]

3. Cho, J.S.; Jang, E.; Lim, D.; Ahn, S.; Yoo, J.; Cho, A.; Park, J.H.; Kim, K.; Choi, B.H. Wide-bandgap nanocrystalline silicon-carbon alloys for photovoltaic applications. Sol. Energy Mater. Sol. Cells 2018, 182, 220-227. [CrossRef]

4. Li, Q.; Yin, X.; Duan, W.; Kong, L.; Liu, X.; Cheng, L.; Zhang, L. Improved dielectric and electromagnetic interference shielding properties of ferrocene-modified polycarbosilane derived SiC/C composite ceramics. J. Eur. Ceram. Soc. 2014, 10, 2187-2201. [CrossRef]

5. Latha, H.K.E.; Udayakumar, A.; Prasad, V.S. Microstructure and electrical properties of nitrogen doped 3C -SiC thin films deposited using methyltrichlorosilane. Mater. Sci. Semicond. Process. 2015, 29, 117-123. [CrossRef]

6. Kim, Y.W.; Kim, K.J.; Kim, H.C.; Cho, N.H.; Lim, K.Y. Electrodischarge-machinable silicon carbide ceramics sintered with Yttrium Nitrate. J. Am. Ceram. Soc. 2011, 4, 991-993. [CrossRef]

7. Zhao, Y.; Li, C.; Liu, J.L.; An, K.; Yan, X.B.; Hei, L.F. The interface and mechanical properties of a CVD single crystal diamond produced by multilayered nitrogen doping epitaxial growth. Materials 2019, 15, 2492. [CrossRef]

8. Chen, C.C.; Wang, F.H.; Chang, S.C.; Yang, C.F. Using oxygen plasma pretreatment to enhance the properties of F-Doped ZnO films prepared on polyimide substrates. Materials 2018, 9, 1501. [CrossRef]

9. Lu, N.; Quan, X.; Li, J.Y.; Chen, X.; Yu, H.T.; Chen, G.H. Fabrication of boron-doped TiO2 nanotube array electrode and investigation of its photoelectrochemical capability. J. Phys. Chem. C 2007, 32, 11836-11842. [CrossRef]

10. Wijesundara, M.B.J.; Stoldt, C.R.; Carraro, C.; Howe, R.T.; Maboudian, R. Nitrogen doping of polycrystalline 3C-SiC films grown by single-source chemical vapor deposition. Thin Solid Films 2002, 419, 69-75. [CrossRef]

11. Chen, J.; Steckl, A.J.; Loboda, M.J. In situ $\mathrm{N}_{2}$-doping of SiC films grown on Si (111) by chemical vapor deposition from organosilanes. J. Electrochem. Soc. 2000, 6, 2324-2327. [CrossRef]

12. Hoshide, Y.; Tabata, A.; Kitagawa, A.; Kondo, A. Preparation of n-type nanocrystalline 3C-SiC films by hot-wire CVD using $\mathrm{N}_{2}$ as doping gas. Thin Solid Films 2009, 12, 3524-3527. [CrossRef]

13. Zhang, J.; Carraro, C. Electrical, mechanical and metal contact properties of polycrystalline 3C-SiC films for MEMS in harsh environments. Surf. Coat. Technol. 2007, 22-23, 8893-8898. [CrossRef]

14. Trevino, J.; Fu, X.; Mehregany, M.; Zorman, C. Low-Stress, heavily-doped polycrystalline silicon carbide for MEMS application. In Proceedings of the 18th IEEE International Conference on Micro Electro Mechanical Systems (MEMS 2005), Miami Beach, FL, USA, 30 January-3 February 2005.

15. Cheng, H.; Tu, R.; Zhang, S.; Han, M.X.; Goto, T.; Zhang, L.M. Preparation of highly oriented beta SiC bulks by halide laser chemical vapor deposition. J. Eur. Ceram. Soc. 2017, 2, 509-515. [CrossRef]

16. Cheng, H.; Yang, M.J.; Lai, Y.F.; Hu, M.W.; Li, Q.Z.; Tu, R.; Zhang, S. Transparent highly oriented 3C-SiC bulks by halide laser CVD. J. Eur. Ceram. Soc. 2018, 9, 3057-3063. [CrossRef]

17. Lai, Y.F.; Cheng, H. Fine-grained 3C-SiC thick films prepared via hybrid laser chemical vapor deposition. J. Am. Ceram. Soc. 2019, 102, 1-11. [CrossRef]

18. Catellani, A.; Calzolari, A. Functionalization of $\mathrm{SiC}(110)$ surfaces via porphyrin adsorption: Ab initio results. J. Phys. Chem. C 2012, 116, 886-892. [CrossRef]

19. Roy, S.; Zorman, C.; Mehregany, M.; Deanna, R.; Deeb, C. The mechanical properties of polycrystalline 3C-SiC films grown on polysilicon substrates by atmospheric pressure chemical-vapor deposition. J. Appl. Phys. 2006, 4, 11-12. [CrossRef]

20. Jha, H.S.; Agarwal, P. Highly crystalline silicon carbide thin films grown at low substrate temperature by HWCVD technique. J. Mater. Sci. Mater. Electron. 2015, 3, 1381-1388. [CrossRef]

21. Carduner, K.R.; Shinozaki, S.S.; Rokosz, M.J.; Peters, C.R.; Whalen, T.J. Characterization of beta-Silicon Carbide by Silicon-29 Solid-State NMR, Transmission Electron Microscopy, and Powder X-ray Diffraction. J. Am. Ceram. Soc. 1990, 8, 2281-2286. [CrossRef] 
22. Koumoto, K.; Takeda, S. High-resolution electron microscopy observations of stacking faults in beta-SiC. J. Am. Ceram. Soc. 1989, 10, 1985-1987. [CrossRef]

23. Lotgering, F. K Topotactical reactions with ferrimagnetic oxides having hexagonal crystal structures-I. J. Inorg. Nucl. Chem. 1959, 9, 113-123. [CrossRef]

24. Ferro, G.; Chaussende, D. A new model for in situ nitrogen incorporation into 4H-SiC during epitaxy. Sci. Rep. 2017, 7, 1-11. [CrossRef] [PubMed]

25. Larkin, D.J.; Neudeck, P.G.; Powell, J.A.; Matus, L.J. Site-competition epitaxy for superior silicon carbide electronics. Appl. Phys. Lett. 1994, 13, 1659-1661. [CrossRef]

26. Tu, R.; Zheng, D.H.; Cheng, H.; Hu, M.W.; Zhang, S.; Han, M.X.; Goto, T.; Zhang, L.M. Effect of $\mathrm{CH}_{4} / \mathrm{SiCl}_{4} \mathrm{ratio}$ on the composition and microstructure of $<110>$-oriented beta-SiC bulks by halide CVD. J. Eur. Ceram. Soc. 2017, 4, 1217-1223. [CrossRef]

27. Ohshita, Y.; Kitajima, $\mathrm{H}$. In situ doped polycrystalline silicon selective growth using the $\mathrm{SiH}_{2} \mathrm{Cl}_{2} / \mathrm{H}_{2} / \mathrm{HCl} / \mathrm{PH}_{3}$ gas system. J. Appl. Phys. 2014, 3, 1989-1992.

28. Feldman, D.W.; Parker, J.H. Phonon Dispersion Curves by Raman Scattering in SiC, Polytypes 3C, $4 \mathrm{H}, 6 \mathrm{H}$, 15R, and 21R. Phys. Rev. 1968, 3, 787-793. [CrossRef]

29. Klein, M.V.; Ganguly, B.N. Theoretical and Experimental Study of Raman Scattering from Coupled LO-Phonon-Plasmon Modes in Silicon Carbide. Phys. Rev. B 1972, 6, 2380-2388. [CrossRef]

30. Irmer, G. Determination of the Charge Carrier Concentration and Mobility in n-GaP by Raman Spectroscopy. Phys. Status Solidi 1983, 2, 595-603. [CrossRef]

31. Yugami, H.; Nakashima, S.; Mitsuishi, A.; Uemoto, A.; Shigeta, M. Characterization of the freecarrier concentrations in doped $\beta$ SiC crystals by Raman scattering. J. Appl. Phys. 1987, 61, 354-358. [CrossRef]

32. Wellmann, P.J.; Weinga, R. Determination of doping levels and their distribution in SiC by optical techniques. Mater. Sci. Eng. B 2003, 1-3, 262-268. [CrossRef]

33. Weingärtner, R.; Wellmann, P.J.; Bickermann, M.; Hofmann, D.; Straubinger, T.L.; Winnacker, A. Determination of charge carrier concentration in $\mathrm{n}$ - and $\mathrm{p}$-doped $\mathrm{SiC}$ based on optical absorption measurements. Appl. Phys. Lett. 2012, 80, 70-72. [CrossRef]

34. Weingärtner, R.; Wellmann, P.J. On the Origin of the Below Band-Gap Absorption Bands in n-Type (N) 4Hand 6H-SiC. Mater. Sci. Forum 2004, 457, 645-648. [CrossRef]

35. Hellmann, B.A.R. SiC absorption of near-infrared laser radiation at high temperatures. Appl. Phys. A 2016, 7,642 .

36. Shi, X.; Chen, L.; Uher, C. Recent advances in high-performance bulk thermoelectric materials. Int. Mater. Rev. 2016, 6, 379-415. [CrossRef]

37. Tan, G.; Zhao, L.D.; Kanatzidis, M.G. Rationally designing high-performance bulk thermoelectric materials. Chem. Rev. 2016, 19, 12123-12149. [CrossRef]

38. Sonntag, H.; Kalbitzer, S. Ion-implantation doping of crystalline 6H-SiC. Appl. Phys. A Mater. Sci. Process. 1995, 4, 363-367. [CrossRef]

39. Yukina, T.; Yukina, T.; Mettaya, K.; Hirokazu, K.; Takashi, G. Electrical and thermal properties of nitrogen-doped SiC sintered body. J. Jpn. Soc. Powder Powder Metall. 2018, 8, 508-512.

40. Pearson, G.L.; Bardeen, J. Electrical properties of pure silicon and silicon alloys containing boron and phosphorus. Phys. Rev. 1949, 5, 865-883. [CrossRef]

41. Wijesundara, M.B.J.; Gao, D.; Carraro, C.; Howe, R.T.; Maboudian, R. Nitrogen doping of polycrystalline 3C-SiC films grown using 1, 3-disilabutane in a conventional LPCVD reactor. J. Cryst. Growth 2003, 259, 18-25. [CrossRef]

(C) 2020 by the authors. Licensee MDPI, Basel, Switzerland. This article is an open access article distributed under the terms and conditions of the Creative Commons Attribution (CC BY) license (http://creativecommons.org/licenses/by/4.0/). 